\title{
Beyond sustainability: cradle-to-cradle business innovation and improvement zones in NW Europe
}

C. A. Booth ${ }^{1}$, A. Oosting ${ }^{2}$, N. Ankrah ${ }^{3}$, F. N. Hammond ${ }^{3}$, K. Tannahill' ${ }^{3}$, C. Williams, H. Smolders ${ }^{2}$, J. Braas ${ }^{2}$, L. Scheepers ${ }^{2}$, A. Kathrani ${ }^{4}$, L. Virdee ${ }^{4}$, T. Kadlecova ${ }^{4}$, O. Lewald ${ }^{5}$, M. Mess ${ }^{5}$,

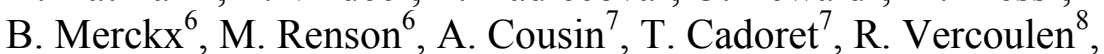
E. Starmans ${ }^{8}$, A. Bertrand ${ }^{9}$, A. Beloussova ${ }^{9}$, L. Mathieu ${ }^{10}$, J.-M. Meulemans ${ }^{11}$ \& J. Schroeder ${ }^{11}$

${ }^{I}$ Department of Construction and Property, University of the West of England, Bristol, UK

${ }^{2}$ Eindhoven Region, The Netherlands

${ }^{3}$ Department of Built Environment, University of Wolverhampton, UK

${ }^{4}$ Institute for Sustainability, London, UK

${ }^{5}$ City of Bielefeld, Germany

${ }^{6}$ Brussels Regional Development Agency, Belgium

${ }^{7}$ Lille Metropole, France

${ }^{8}$ Municipal Authority of Venlo, The Netherlands

${ }^{9}$ Centre de Recherche Public Henri Tudor, Luxembourg

${ }^{10}$ Ministry of Sustainable Development and Infrastructure, Luxembourg

${ }^{11}$ Ecoparc Windhof GIE, Luxembourg

\begin{abstract}
'Sustainability' has defined the approach towards dealing with resource deprivation and climate change over the past three decades, promoting 'less bad' strategies that aim to mitigate damage. Cradle-to-Cradle (C2C) offers an alternative approach that focuses on doing 'good' by promoting continuous loops, reliance on current solar income, and diversity. It is argued that this philosophy offers the best opportunity to make a big beneficial footprint on this planet rather than just reducing the damage being done. Whilst this approach has
\end{abstract}


seen some application in various products including the delivery of some buildings where it has positively and significantly impacted the triple bottom line, it is yet to be scaled up for wider application to whole sites. It is against this background that the $\mathrm{C} 2 \mathrm{C}$ BIZZ project is being funded by the European Commission as part of the INTERREG IVB North-West Europe (NWE) Programme to explore the possibilities of wide scale application of $\mathrm{C} 2 \mathrm{C}$ using a network of business sites across NWE. This paper provides some insight into the contents of this project, and argues that this project will allow for the formation of a virtual transnational $\mathrm{C} 2 \mathrm{C}$ demonstration business site that will provide a blueprint for all future $\mathrm{C} 2 \mathrm{C}$ applications in the built environment in NWE through the development of a suite of $\mathrm{C} 2 \mathrm{C}$ tools.

Keywords: cradle-to-cradle (C2C), C2C BIZZ, energy, diversity, lifecycle analysis, waste.

\section{Introduction}

The concept of sustainability has become foremost in the minds of many politicians and economists over recent decades (Malovics et al. [1]) and, concomitantly, the wider issue of sustainable development has been addressed at copious global arenas. Sustainability is a multifaceted issue. From an economic development viewpoint, it is defined by the United Nations World Commission on Environment and Development (UNWCED [2]) (commonly known as the Brundtland Report) as "Development that meets the needs of the present without compromising the ability of future generations to meet their own needs" When considering business enterprises, sustainable development has been defined by The International Institute for Sustainable Development, Deloitte \& Touche and the World Business Council for Sustainable Development (WBCSD) as " [...] adopting business strategies and activities that meet the needs of the enterprise and its stakeholders today, while protecting, sustaining and enhancing the human and natural resources that will be needed in the future" (Malovics et al. [1]).

What this means is, the implementation of management strategies that will allow businesses to focus not only on fiscal considerations but focus more on what has become known as 'the triple bottom line' encompassing environmental protection and social equity in conjunction with economic success (McDonough and Braungart [3] and Cowan et al. [4]). This link between sustainability and economic performance is particularly significant within a European context, as the European Commission (EC) has recently introduced initiatives to promote corporate social responsibility (CSR) and sustainability (Wagner [5]). It has also recently published a report entitled "A new policy on corporate social responsibility", in which it states that in order to fully meet their social responsibilities, businesses "should have in place a process to integrate social, environmental, ethical and human rights concern into their business operations and core strategy in close collaboration with their stakeholders". The concept of CSR is a relatively new one that looks at a business's contribution to sustainable development, while highlighting that corporate strategy must consider not only 
the financial needs of its stakeholders and consumers, but also their societal and environmental concerns (Hedigar [6]).

This entire shift towards sustainable development and CSR has been driven largely by concerns over climate change and the fear that current levels of consumption, waste and carbon emission would ultimately lead to an irreversible tipping point (Stern [7]). The development and use of the built environment has played a major role in this state of affairs. It has been estimated that as much as $40 \%$ of all carbon emissions come from domestic and non-domestic buildings (Carbon Trust [8]). In the UK for instance it is reported that each year as much as 420 million tonnes of material resources go into the development of the built environment (Environment Agency [9]), a quarter of which becomes waste with 19 million tonnes being material delivered to building sites but never used at all. Clearly, addressing some of these issues of the built environment will make a significant impact on climate change.

In spite of all the summits, agreements and initiatives that have taken place over the past three decades not much progress has been made under the sustainable development agenda towards redressing this global problem, particularly in relation to approaches to the development and use of the built environment. In one respect it could be argued that the cost of change has been a major challenge. In another respect it could be argued that the entire sustainable development approach is underpinned by a development paradigm that is still rooted in the traditional cradle-to-grave philosophy which ultimately means that there will always be waste at the end of product lifecycles with detrimental impacts on the environment, society and the economy, notwithstanding the sustainability initiatives implemented.

This article provides insights into a new development paradigm - the cradleto-cradle philosophy (McDonough and Braungart [3]) - which it argues offers a better foundation for making a positive and beneficial impact on the profitability, people and the environment because it focuses on 'effectiveness' and not just 'efficiency'. In particular the article examines the potential application of this philosophy to the built environment and then presents the aims, objectives and activities of an EU-funded (INTERREG IVB) project, which is investigating profitable and future-proofing of business site developments in NW Europe.

\section{Lifecycle analysis: insights of the cradle-to-cradle concept}

All products are defined by a cycle. Traditionally these cycles have been defined in linear terms from extraction of raw materials to final disposal at the end of the product's life. At each stage of this cycle, products have an impact on the environment, sometimes in beneficial ways but very often also in adverse ways. The essence of lifecycle analysis has thus been to systematically assess the impacts on the environment and society as a whole, of products at each of the stages that define their lifecycle so that the best (or rather most efficient) tradeoffs can be made to minimise adverse impacts whilst maintaining functionality.

The implementation of environmentally friendly strategies (which are outcomes of such trade-off choices) thus tends to focus on managing the 
negative effects of the industrial process. It assumes a linear cradle-to-grave process; whereby, products and material flows ultimately create waste that will require disposal. Even when products are recycled, this often takes the form of an end-of-pipe solution, which results in a downgrade in material quality. This maintains the linear dynamic of material flow and ultimately results in only delaying the need for disposal. The product's lifespan has been increased but does not maintain its status as a resource. It also assumes a system; whereby, the depletion of resources and negative environmental impacts can be slowed but the ultimate result will be the same, a wasted planet with a destroyed ecosystem and no natural resources (Braungart et al. [10]). It has been suggested by McDonough and Braungart [3] that the resulting agenda is one based on trying to be 'less bad', and they pose the question, 'is being less bad being good?' They propose that the answer to this question is no, and a palliative approach is not sufficient. The triple bottom line approach to sustainability is often, unfortunately, more a measure of the degree to which a company has minimised liability. They suggest a change in strategy that creates a system of intelligent design, in which products and industrial processes create wholly positive effects (i.e. a large beneficial ecological footprint). This new approach could be termed sustaining, rather than sustainable, and would result in a change in perspective from the 'triple bottom line' to the 'triple top line'. Introducing a process that involves a more positive approach to all aspects of design and desire to enhance the environmental and social aspects, rather than just minimise any negative impact.

While the triple bottom line is usually a balancing act aimed at compromising, McDonough and Braungart [3] have used a fractal triangle (Figure 1) to illustrate the interconnectedness of all three-strategy drivers and suggest that embracing all three can ultimately result in enhancing all of them. In their discussions with industry leaders, they move round the fractal triangle as they plan a new product or system and inquire how it can generate value in each category. This shifts the focus from negative judgements to questions of quality. The result is a strategy that shifts from the cradle-to-grave nature of a 'patched up' century old industrial model, to a cradle-to-cradle design. This new concept rejects the notion that the end result would be, ultimately, the destruction of the natural world. They propose a system that is cyclic in nature and self-contained, one that will resonate with natural systems. This is demonstrated effectively when they discuss their involvement with the Ford motor company and the restoration of the Rouge river plant in Michigan. The decision was taken (in 1999) to transform the ageing industrial complex into "an icon of the $21^{\text {st }}$ century industry". The use of the fractal triangle allowed engineers to focus on maximising profits by including design decisions that also maximised social and ecological value. Design questions were proactive in nature rather than merely trying to meet their environmental and social responsibilities to minimise liability. They attempted to design a site that would create habitat, increase species diversity and create an aesthetic social space. The result of this was a site that had 450,000 $\mathrm{ft}^{2}$ of living roof, porous paving and constructed wetlands. All of which enhanced the social and environmental aspects of the site, whilst 
reducing the costs associated with expensive controls and treatments for stormwater runoff (McDonough and Braungart [3]). This type of thinking calls for a different attitude and approach to product design and requires an effective collaboration with like-minded business partners throughout the product chain (Braungart et al. [10]). However, the final result has been described by McDonough and Braungart [3] as "a new standard of quality, adding ecological intelligence, social justice and the celebration of creativity to the typical design criteria of cost, performance, and aesthetics. Design driven by these positive aspirations could lay the foundation for a truly inspiring era in which we transform industry by remaking the way we make things". The result of which, is a world where profit is no longer at odds with environmental and social concerns and nature and commerce can thrive in harmony.

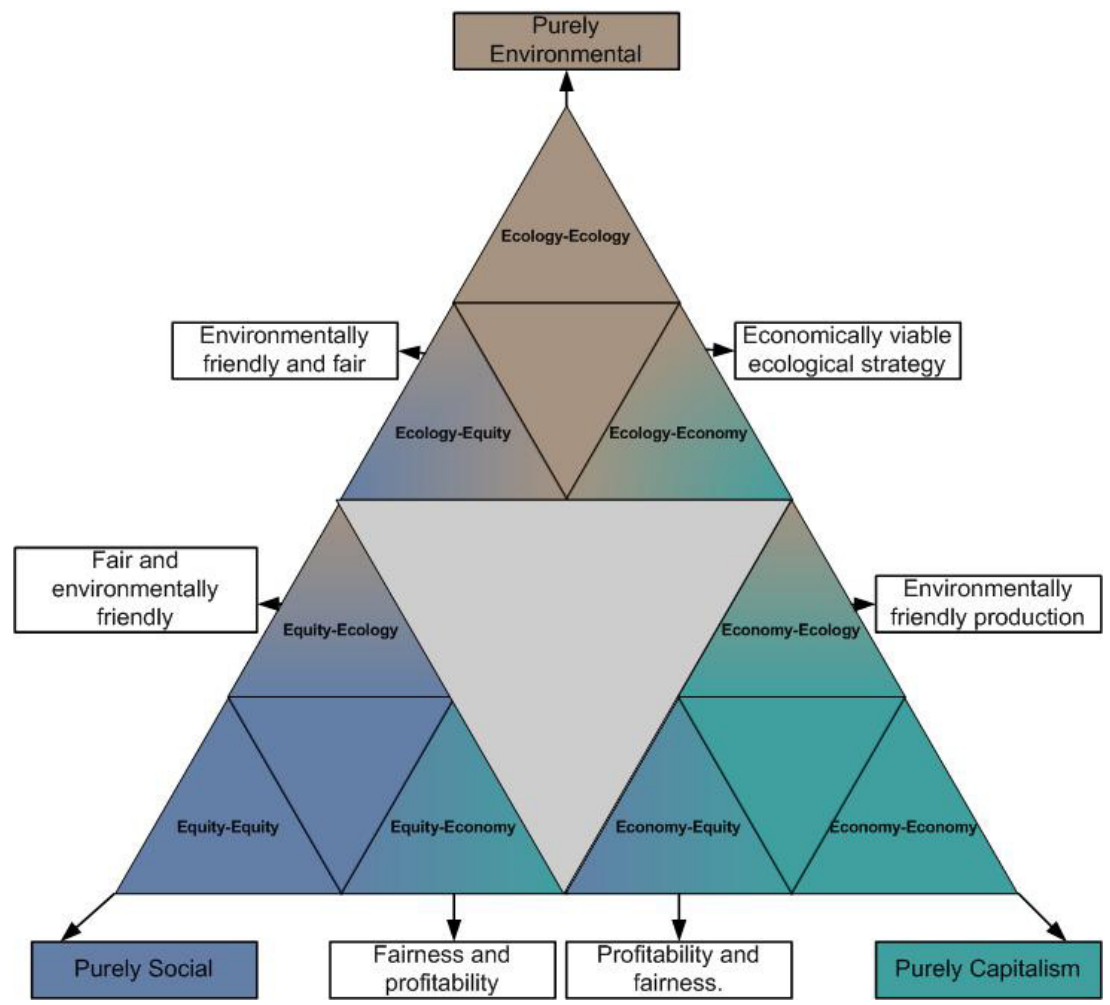

Figure 1: $\quad$ Fractal triangle (adapted from McDonough and Braungart [3]).

The example of the Ford plant provided above demonstrates quite vividly that in spite of its inherent complexity, the built environment naturally lends itself to the application of this philosophy in the design and development of buildings and infrastructure to support human activities. By virtue of its long lifecycles and substantial impact on the triple bottom line, the successful application of $\mathrm{C} 2 \mathrm{C}$ to the design and development of the built environment offers the chance to secure 
a huge beneficial impact over the long term. In spite of this there is no evidence of systematic application of this philosophy in the built environment beyond an ad hoc and piecemeal approach to individual random buildings, and certainly no application to entire sites. It is to counter this that it is considered necessary to have a roadmap that sets out in clear terms the business case and provides the toolkits to support the wider and more systematic application of $\mathrm{C} 2 \mathrm{C}$ to the built environment particularly at estate or business site level, and this is the inspiration for the $\mathrm{C} 2 \mathrm{C} \mathrm{BIZZ}$ project.

\section{European business innovation and improvement zones}

\subsection{The C2C BIZZ project}

The C2C BIZZ Project (EU project code 204G) is funded by the European Commission as part of the INTERREG IVB North-West Europe Programme (2010-2014). The programme provides opportunities for transnational cooperation of public authorities, private sector firms, universities and research institutes, communities and NGOs to find innovative ways to tackle shared challenges. With the intention of enabling European competitive development, the programme adheres to the vision of the 'Europe 2020' strategy through the priorities of smart growth (knowledge and innovative economies), sustainable growth (resource-efficient economies) and inclusive growth (high-employment economies).

The concept of cradle-to-cradle business strategies is relatively new and minimal framework exists within which businesses can operate. While the philosophy has been realised in a few products and buildings, it has not yet been realised on a business site level. The aim of this project is to enhance the current implementation of $\mathrm{C} 2 \mathrm{C}$ methods in the built environment and to accelerate the development of $\mathrm{C} 2 \mathrm{C}$ solutions and applications on business sites. Different innovative aspects of transition towards $\mathrm{C} 2 \mathrm{C}$ are being studied, developed and tested on pilot sites. When combined, the pilot sites will form one complete transnational $\mathrm{C} 2 \mathrm{C}$ business site and a new form of site management in NorthWest Europe (NWE). At present, there are notable differences between the NWE countries when adopting $\mathrm{C} 2 \mathrm{C}$ strategies. This project aims to combat this by encouraging knowledge building and exchange between member countries. Transforming business sites to $\mathrm{C} 2 \mathrm{C}$ business sites requires a transnational approach involving the creation of $\mathrm{C} 2 \mathrm{C}$ tools and testing on pilot sites in different geographical environments. This means greenfield and brownfield sites but also different institutional and cultural settings. As the transition to a $\mathrm{C} 2 \mathrm{C}$ site needs to be tested and made step-by-step, the pilots each form one step in the process. The partners are working together to create an holistic application strategy (roadmap) that will be applicable to all future NWE business site redevelopments. Inter-country co-operation will ultimately result in transnational financial, managerial and technical $\mathrm{C} 2 \mathrm{C}$ tools.

The aim of $\mathrm{C} 2 \mathrm{C}$ BIZZ is to enhance the current implementation of $\mathrm{C} 2 \mathrm{C}$ methods in the NWE built environment and to accelerate the development of 
$\mathrm{C} 2 \mathrm{C}$ solutions and applications on business sites. The three $\mathrm{C} 2 \mathrm{C}$ principles will be applied to the entire process of business area (re)development. $\mathrm{C} 2 \mathrm{C}$ business sites have a positive impact on environment, society and economy and are future proof. This will be achieved through the following objectives: (i) Develop a knowledge base for projects in the evolution of business sites to $\mathrm{C} 2 \mathrm{C}$ sites by increasing and centralising knowledge, creating networks, and developing tools for planning, building and managing $\mathrm{C} 2 \mathrm{C}$ business sites, resulting in transnational $\mathrm{C} 2 \mathrm{C}$ demonstration sites; (ii) Eliminate waste. Waste is re-used as a resource for new products, buildings and energy instead. C2C will develop, test and evaluate continuous loops of materials, energy and waste management systems on project sites; (iii) Enjoy renewable energy. All energy sources will be renewable. Business sites will produce, instead of consume, energy, by designing and implementing energy generation protocols, installing smart grids and using new local energy sources; (iv) Celebrate diversity. Develop new C2C design methods for more flexible and durable business sites and buildings by implementing the $\mathrm{C} 2 \mathrm{C}$ diversity principle; and (v) Disseminate $\mathrm{C} 2 \mathrm{C}$ best practices and lessons learned within the project by developing a ready-to-use roadmap and business case and an expert and stakeholder network to ensure transferability and distribution of project results.

\subsection{Project activities: work packages}

The overriding principles of the $\mathrm{C} 2 \mathrm{C}$ project are grouped into four primary workgroups, the first of these being knowledge building and transfer. This is an integral part of the processes and will ultimately produce an holistic application strategy (roadmap) for other businesses to use. As figure 2 demonstrates, work package (WP) 1 should be aligned horizontally above the other three thematic WPs. The aim of WP1 is to transfer the knowledge needed to perform the actions and investments in the other WPs. This will be achieved by: (1) Centralising and increasing the knowledge relevant and applicable on site-level by developing a central C2C Knowledge Centre in Venlo with local nodes in partner regions; (2) Creating networks of $\mathrm{C} 2 \mathrm{C}$ experts and stakeholders; (3) Training and observing partners; and (4) developing specific technical, managerial and financial tools for planning, building and managing $\mathrm{C} 2 \mathrm{C}$ business sites within the project and for future application. The process is cyclic in nature and information gleaned from these objectives will flow to the thematic WPs where it will be tested and results will, in turn, flow from the thematic WPs back into the knowledge building and transfer stage and aid in design of the roadmap.

The second work package (WP2) is designed to develop methods to apply the first $\mathrm{C} 2 \mathrm{C}$ principle (waste $=$ food) on business sites. All excess material from production processes should become input for new products or become food for a new natural (composition) or technological process. Likewise, building materials are continuously re-used as a resource base. A continuous loop is created and waste is eliminated. The actions in this WP are primarily focused on designing and implementing protocols and facilities for continuous loops. This involves research on product design, product processes, materials and the production processes of all companies throughout the product chain. This WP 
has a strong focus on management of material flows and informing and engaging businesses. A full waste-free pilot, converting secondary waste streams to energy for the site will be made operational on the demo site in the UK.

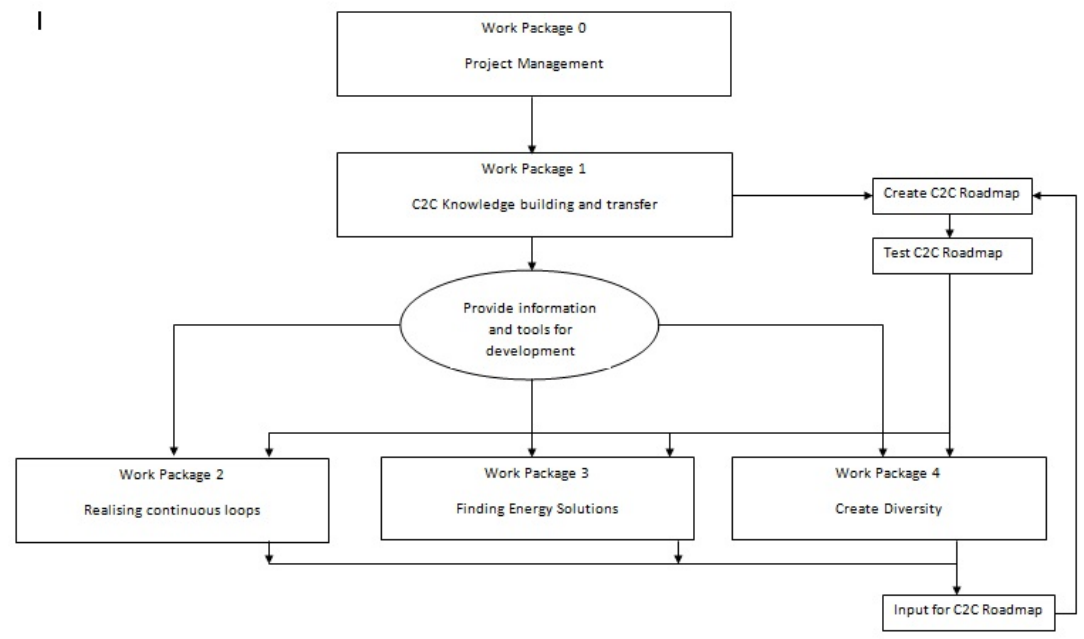

Figure 2: $\quad$ Work package structure of the $\mathrm{C} 2 \mathrm{C}$ BIZZ project.

The third work package (WP3) is designed to develop applications for the second C2C principle "enjoy renewable energy". In C2C theory, solar energy is a prime example of a renewable power source effectively used by both nature and man. Other types of renewable energy are also to be tapped. The WP objective translates the $\mathrm{C} 2 \mathrm{C}$ principle into ways to change the power consumption of business sites. $\mathrm{C} 2 \mathrm{C}$ business site should become generators of renewable energy instead of energy consumers. The pilot site for this will be at the Ecoparc Windholf in Luxembourg, where a smart grid for renewable energy will be developed and tested.

The fourth work package (WP4) embraces the third C2C principle celebrating diversity - states that it is diversity that creates the competitiveness of nature. Because of the variety in flora and fauna, the natural system is flexible and able to adapt quickly to changes. $\mathrm{C} 2 \mathrm{C}$ argues that it is the same diversity approach that shapes the competitiveness of products, economic systems and business sites. Current business site designs are often ill-prepared for geographic movements of production chains. Often they are concentrated on their current economic function and profitability. Business sites offer great contrast with nature. Concrete instead of vegetation, monofunctionality instead of a multi-use environment. The aim of WP4 is to create spatial designs to (re)develop business sites in a $\mathrm{C} 2 \mathrm{C}$ manner, incorporating diversity, so that they become more flexible in terms of current and future use, different types of users, more accessible and mixable with other forms of spatial use and, hence, evolve to remain competitive. 


\subsection{Project activities: the pilot sites}

There are various pilot sites throughout the partner countries designed to test aspects of the $\mathrm{C} 2 \mathrm{C}$ principles and gather knowledge output. The primary venue (investment) is the $\mathrm{C} 2 \mathrm{C}$ Knowledge and documentation centre located in the city of Venlo in the Netherlands. The centre will have a knowledge, training and demonstration function, and will act as a physical and organisational hub in the C2C BIZZ network. It will be a reference point for the expert team, partner staff and stakeholders for training, networking and knowledge gathering. It will mainstream the physical investments and applications of $\mathrm{C} 2 \mathrm{C}$ principles with the full cycle. Included will be an interactive demonstration facility, where the full $\mathrm{C} 2 \mathrm{C}$ cycle can be demonstrated and how the pilots together form an international C2C business site. It will also feed the roadmap and business case with application and research input.

\subsubsection{Pilot site one: Luxembourg (LU)}

The Ecoparc Windhof GIE in Luxembourg is a business site where new, revolutionary offices (solarwind and $\mathrm{CO}_{2}$ neutral buildings) are integrated into a zone with other businesses. The site aims to act as a power generator in the near future through on-site renewable energy production. C2C BIZZ will invest the infrastructure for the smart grid-based energy distribution system that will consist of and intelligent monitoring system that will keep track of energy flows and usage. There are two different pilots being carried out on this site. One focuses on renewable energy and the second focuses on avoiding waste. Ecoparc Windhof GIE propose to research and implement energy production and distribution facilities increasing reliability, efficiency and safety of the power grid, enabling decentralised power generation and enabling supplier selection. In conjunction with this, it will also be used to pilot the optimum reuse of company waste streams to reuse as primary material input in production processes, reducing and possibly eliminating waste on-site. The main goal of the continuous loop pilot is not to create energy from waste, like the focus of the UK demonstrator pilot, but to find synergies between companies to exchange materials to reduce/eliminate material leftovers at the maximum possible.

\subsubsection{Pilot site two: France (FR)}

This pilot site deals with the $\mathrm{C} 2 \mathrm{C}$ concept as a whole and the ecological diversity concept and will take place on a Brownfield redevelopment site in La Lainiere. This site contains the remains of a former textile mill, a structure that has potential as a diverse inner-city multi-tenant business area. It is planned that the inner structure will be flexible and reversible so it is designed for a change of (economic) use. It will further use materials that are reusable after the lifespan of the building (such as $\mathrm{C} 2 \mathrm{C}$ polymers). Incorporated will be flexible innovative infrastructure for water, energy and warmth, accommodating (future) recycling on-site, power generation and change of users. There will also be diversity in spatial design, incorporating social and environmental spaces to create a competitive and diverse economic, social and ecological climate. The site design 
incorporates the full $\mathrm{C} 2 \mathrm{C}$ cycle but focuses on application of the 'diversity' principle: flexibility and prolonging life-span.

\subsubsection{Pilot site three: UK}

The Sustainable Industries Park (SIP) is a site within the Thames Gateway Eco region and Green Enterprise District, is a 25 ha Business Park aiming to create the largest concentration of environmental industries and technology businesses in the UK. This site will be a pilot for testing the optimal reuse of by-products (secondary waste streams) from a variety of Energy from Waste (EfW) processes. It will have two key working elements: (1) A workbench facility which investigates the optimal reuse of by-products from EfW processes for research on uses of low-grade residues such as 'char' from gasification plants or 'digestate' from anaerobic digestion and exploring routes to recover and ruse metals from bottom ash and recovering waste water and higher grade gases; and (2) A secondary waste stream continuous loop system demonstration. A feasibility stage will identify the optimal demo process - both of existing and future tenants of the SIP. The demo will be used to illustrate how a continuous loop system could be achieved for the onsite EfW facility itself.

\section{Discussion}

NWE is Europe's most densely inhabited and developed area (40\% of the EU27 population housed on $20 \%$ of the EU27 land area). Industry is a major contributor to $\mathrm{CO}_{2}$ emissions, environmental degradation and climate change. Business sites and operations have a considerable share in land use and resources. While they are necessary for economy, they fulfil a negative role for environment and society. Their monofunctional design makes them obsolete when production processes shift to other places and production is organized so that material leftovers are considered without value. The challenge is to change the negative impact of business sites and production into a positive one, for economy (innovation, competitiveness), environment (improvement of nature quality and biodiversity) and society (multifunctional, social inclusion etc.). $\mathrm{C} 2 \mathrm{C}$ is a holistic framework that creates systems that are not only eco-efficient but essentially waste-free: a revolutionary change from traditional 'cradle to grave' approach. Rather than minimizing material and energy flows, C2C proposes transforming products and material flows so that a workable relationship between ecological systems and economic growth is made possible.

To develop a $\mathrm{C} 2 \mathrm{C}$ business site is innovative by itself. $\mathrm{C} 2 \mathrm{C}$ has so far been applied to products, buildings or companies, but not on business site level. A new way of site management and development for business sites will be developed to interconnect the $\mathrm{C} 2 \mathrm{C}$ principles on site level. C2C means $100 \%$ continuous loops eliminating waste, using water and warmth leftovers of companies, energy creation from sustainable sources with intelligent energy distribution, implementing integrated designs for business sites with long-term added value for economy, environment and society: innovative approaches on 
project-level which combined will contribute to development of an holistic C2C application strategy for business sites (roadmap).

\section{Future work}

Further information can be obtained from the C2C BIZZ Project website (www.c2cbizz.com), where details of future publications, project findings and partner events will appear.

\section{Conclusions}

An overview of the $\mathrm{C} 2 \mathrm{C} \mathrm{BIZZ} \mathrm{project} \mathrm{has} \mathrm{been} \mathrm{provided.} \mathrm{The} \mathrm{project} \mathrm{is} \mathrm{funded}$ by the European Commission as part of the INTERREG IVB North-West Europe Programme. The aim of the project is to create a new framework within which businesses can (re)develop business sites in line with the cradle-to-cradle philosophy. This approach represents a paradigm shift from the dominant sustainability approach, and it is believed will offer substantial and tangible benefits that cut across the triple bottom line, not just a few improvements of waste management, energy generation and biodiversity which is what the sustainability approach offers. Different innovative aspects of this transition towards $\mathrm{C} 2 \mathrm{C}$ are being studied, developed and tested on pilot sites throughout participating countries - A continuous-loops system (UK), smart-grid distribution of sustainable energy (LU) and diversity design to redevelop an existing industrial site (FR). Combined they will form one complete virtual transnational $\mathrm{C} 2 \mathrm{C}$ demonstration business site that will be an example for $\mathrm{C} 2 \mathrm{C}$ possibilities in NWE.

Besides the development of innovative $\mathrm{C} 2 \mathrm{C}$ implementation tools, it is expected that a roadmap or blueprint will emerge for the (re)development of such sites in NWE which will inter alia also set out new approaches of site management and stakeholder management. This is a hugely important dimension given that the business site is one big system with many interactions and crosslinks, and as a result will involve active participation from many different stakeholders (planners, architects, builders, governments, energy providers etc.). Ordinary business site planning and management regulations will clearly need to be put aside and new ways developed to complement the changing paradigm of $\mathrm{C} 2 \mathrm{C}$ business site development and use.

\section{Acknowledgement}

All the authors would like to acknowledge and thank the European Commission for the financial support awarded to the $\mathrm{C} 2 \mathrm{C}$ BIZZ Project (EU project code 204G). 


\section{References}

[1] Malovics, G., Csigene, N.N. and Kraus, S. (2008) The role of corporate social responsibility in strong sustainability. Journal of Socio-Economics, 37, 907-918.

[2] United Nations World Commission on Environment and Development (1987). Our Common Future (Brundtland Report). Oxford: Oxford University Press.

[3] McDonough, W. and Braungart, M. (2002) Design for the Triple Top Line: New Tools for Sustainable Commerce. Corporate Environment Strategy, 9, 251-258.

[4] Cowan, D.M., Dopart, P., Ferracini, T., Sahmel, J., Merryman, K., Gaffney, S. and Paustenbach, D. (2010) A cross sectional analysis of reported corporate environmental sustainability practices. Regulatory Toxicology and Pharmacology, 58, 524-538.

[5] Wagner, M. (2010) The role of corporate sustainability performance for economic performance: A firm-level analysis of moderation effects. Ecological Economics, 69, 1553-1560.

[6] Hediger, W. (2010) Welfare and capital-theoretic foundations of corporate social responsibility and corporate sustainability. The Journal of SocioEconomics, 39 518-526.

[7] Stern, N. (2006a) The Economics of Climate Change, Cambridge University Press, Cambridge, http://www.hm-treasury.gov.uk [Accessed: 12/01/07].

[8] Carbon Trust (2010) Buildings policy, http://www.carbontrust.co.uk/policylegislation/Business-Public-Sector/Pages/building-regulations.aspx [Accessed: 01/08/10].

[9] Environment Agency (2003) Sustainable construction: Position statement, environment agency, http:/www.environment-agency.gov.uk/static /documents/Research/ea_sustainable 908180.pdf, [Accessed: 01/05/10].

[10] Braungart, M., McDonough, W. and Bollinger, A. (2007) Cradle-to-Cradle design: creating healthy emissions - a strategy for eco-effective product and system design. Journal of Cleaner Production, 15 1337-1348. 